\title{
Development of a New Superheated Steam System with Micro Water Droplet and Its Application for Blanching of Potato
}

\author{
Isobe, S. ${ }^{1}$, Sotome, I. ${ }^{1}$ and Ogasawara, Y. ${ }^{2}$ \\ ${ }^{1}$ National Food Research Institute, Kannondai 2-1-12, Tsukuba 305-8642, Japan, \\ e-mail:seiichi@affrc.go.jp \\ ${ }^{2}$ Taiyo Seisakusho Co., Shimizukawa 226-10, Hokuto 041-1221, Japan
}

\begin{abstract}
Applications of superheated steam for food processing have been studied in recent years with several advantages. A new oven system, which generates superheated steam with micro droplets of hot water (Aqua-gas), was achieved spraying heated water into a heating chamber filled with the superheated steam. It was expected that the micro-droplets increased the heat transfer coefficient of the heating medium. It was also expected that water content of foods processed with this oven could be controlled by regulating the amount of the micro droplets in the superheated steam. Heat transfer rates of the Aqua-gas and the superheated steam maintained at $115^{\circ} \mathrm{C}$ were measured based on surface temperature of a heat flowmeter. The heat transfer rate of the Aqua-gas was larger than that of the superheated steam in the case the temperature of the heat transfer boundary was low. In addition the drying rate of the food sample was lower in the case of the Aqua-gas due to the effect of the micro droplets. An application of this new Aqua-gas system for the blanching of the potato was examined. The potatoes were blanched by the Aqua-gas, superheated steam of $115^{\circ} \mathrm{C}$, and boiling hot water. The changes in the color, the rheological properties and the micro structure of the potatoes blanched by the Aqua-gas and the superheated steam were smaller than the potatoes blanched by the hot water. The weight loss of the potato was small in the Aqua-gas and the hot water. In addition, Bacillus subtilis spores were pasteurized effectively by the Aqua-gas.
\end{abstract}

\section{INTRODUCTION}

Superheated steam has been studied for food processing in these days since it has various advantages. For instance, the superheated steam transfer the heat to the food products efficiently by condensation and by gas radiation, and the heating system under low oxygen environment is easily achieved by the superheated steam. The superheated steam has been applied for blanching, drying and pasteurization of the food by several researchers (Burg and Fraile, 1995; Fraile and Burg, 1997a; Fraile and Burg, 1997b; Iyota et al., 2003; Markowski et al., 2003; Hung et al., 2004; Iyota et al., 
2005), and now the superheated steam is expected to be applied more extensively in the field of the food processing. In order to extend the application of the superheated steam, we have developed a new oven system using the superheated steam and micro droplets of hot water. In this system, two phase heating medium of the superheated steam and the hot water has been achieved under the normal pressure by spraying the water, which is boiling at a temperature higher than $100{ }^{\circ} \mathrm{C}$ under high pressure. It was expected that the micro droplets increased the heat transfer rate of the heating medium as the water has higher quantity of the heat per unit volume. It was also expected that the water content of the food product processed with this oven system could be controlled by regulating the amount of the micro droplets in the superheated steam. In case of the ordinal superheated steam heating, the drying rate of the food product depends on the heat flow into the product; therefore it is difficult to achieve optimum moisture content of the product and the processing with the optimum heating time and with the optimum temperature simultaneously. In contrast, the new oven system enables to control the moisture content of the product easily. The quality and the yield of the product will be consequently improved by this system.

In this study, the objectives were two holds. The first objective was to clarify the fundamental properties of this new heating medium. In this study, we called this heating medium 'Aqua-gas'. The heat transfer rate of the Aqua-gas was measured and it was compared with that of the ordinal superheated steam and hot dry air. Since the heat transfer rates of the Aqua-gas and the superheated steam were supposed to depend on the temperature of the product, a temperature controllable heat flowmeter was designed. The dependencies of the heat transfer rate of the heating mediums were investigated with the heat flowmeter. The drying properties of the Aqua-gas, the superheated steam and the hot air were also examined through the measurement of the drying rates of the model food sample during the heating. In addition, the micro droplets of the hot water in the Aqua-gas were observed with a high speed camera. Diameters and velocities of the micro droplets were measured from the recorded movies.

The second objective of this study was the application of this Aqua-gas system for the blanching of potato. The amount of the distribution of the potato have a seasonal variation, hence the stable distribution of the potato through all the year is desired. Today, we can store the potato up to seven or eight months at low temperature, however the period is not satisfactory yet. In addition, sugar content of the potato increases by the low temperature storage, which induces synthesis of acrylamide during frying (Chuda et al., 2003; Ohara-Takada et al., 2005). The blanching is one of the methods to solve the problems mentioned above, and it has been studied by several researchers (Arroqui et al., 2002; González-Martínez et al., 2004). In this study, the potatoes were blanched by the Aqua-gas, the ordinal superheated steam and the hot water. The 
temperature distribution of the whole potato was measured, and the temperature profiles inside the potatoes were compared. A peroxidase activity in the processed potato was also measured. The peroxidase causes the off-flavor of the vegetable, and it is often used as the indicator of the blanching because of its high concentration in the vegetable tissue and its high thermal stability (Burnette, 1977; Anthon and Barrett, 2002; Severini et al., 2005). Rheological properties, color and weight loss of the processed potatoes were also measured. Microstructures of the potatoes were observed by a scanning electron microscope. In addition, active Bacillus subtilis spore on the blanched potato were counted.

\section{MATERIALS AND METHODS}

\section{Aqua-gas system}

Figure 1 shows a schematic drawing of the Aqua-gas heating chamber. The heating chamber was filled with the super heated steam of normal pressure. One or more heaters were installed in the chamber, and the heaters were used to maintain the temperature of the superheated steam inside the chamber and to heat the supplied water. The water was supplied through a heating pipe by a plunger pump. The pressure inside the heating pipe was high; hence the water was boiled at the temperature over than $100{ }^{\circ} \mathrm{C}$. In case the supplied water was not completely evaporated by the heater before it was injected to the heating chamber, the boiling water and the saturated steam inside the pipe were sprayed into the heating chamber through a nozzle. The saturated steam expanded adiabatically and its temperature decreased, consequently, it became the superheated steam as the pressure of the steam was normal. The hot water was atomized by the expanding steam, and it was scattered into the superheated steam as the micro droplets.

Being heated by the surrounding superheated steam and the radiation from the heater, the micro droplets evaporated and became the superheated steam at last. However, by spraying the hot water continuously and by controlling the heater temperature, we could maintain the mixture of the two phase status, the superheated steam and the micro droplets. The increased superheated steam due to the evaporation of the micro droplets was exhausted from the heating chamber.

In this study, the temperature of the superheated steam phase was set to $115^{\circ} \mathrm{C}$, and the water supplying rate was from 50 to $60 \mathrm{~m} / / \mathrm{min}$. Since the micro droplets were not supply when the water supplying rate was reduced to $35 \mathrm{ml} / \mathrm{min}$, it was approximated that 30 to $40 \%$ of the supplied water was sprayed as the micro droplets. In this condition, the pressure inside the heating pipe was around $0.25 \mathrm{MPa}$, and the temperature inside the pipe was around $130^{\circ} \mathrm{C}$, which was the saturated temperature at the pressure. The volume of the chamber was about $180 \mathrm{l}$, and the heating medium was 
stirred by a fan installed inside the chamber.

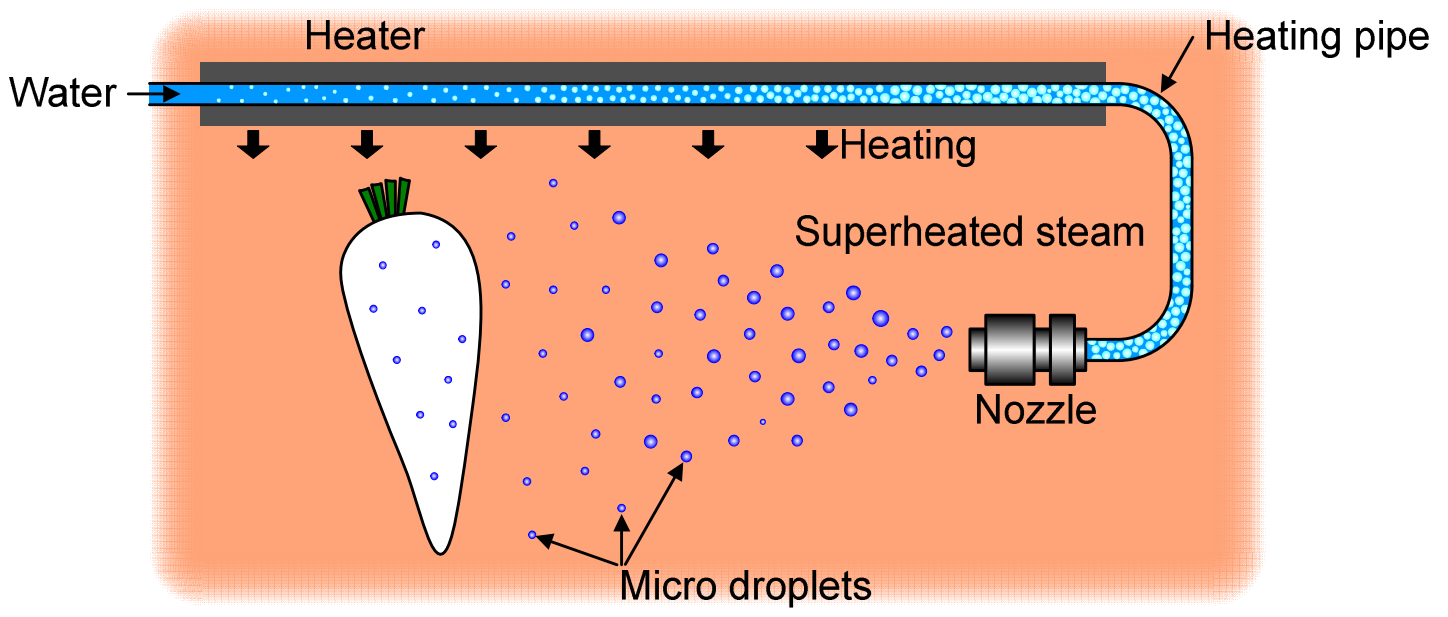

Fig. 1 A schematic drawing of the inside of the Aqua-gas heating chamber.

\section{Measurement of the heat transfer rate}

In order to measure the heat flux from the heating mediums to the materials, a temperature controllable heat flowmeter was designed. Figure 2 (A) shows a sectional drawing of the heat flowmeter, and figure 2 (B) shows a diagram of the whole heat flow measurement system. The heat flowmeter was a rectangular box $(15 \times 15 \times 30$ $\mathrm{mm}$ ), and a copper plate was attached on the box. The copper plate was cooled by coolant circulated inside the box. The heat flowmeter was installed inside the heating chamber of the oven system. The coolant was supplied from a thermoregulator outside of the heating chamber. Under this condition, the heat flowed steadily from the heating medium to the coolant through the copper plate. The temperatures of both surface of the copper plate $\theta_{2}$ and $\theta_{3}$ were measured by thermocouples, which were composed by constantan wires attached on the copper plate. The temperature of the heating medium $\theta_{1}$ and that of the coolant $\theta_{4}$ were measured by the thermocouples.

The heat transfer rate was calculated as follow. The heat flux through the copper plate was expressed by the following equation:

$$
q=\frac{\lambda}{d}\left(\theta_{2}-\theta_{3}\right)
$$

where $\lambda$ was the heat conductivity of the copper and $d$ was the thickness of the copper plate. Under the assumption that the total heat transfer from the heating medium was equal to the heat flux through the copper plate, the total heat transfer rate $h$ was expressed by the equation as follow: 


$$
h=\frac{\lambda}{d} \cdot \frac{\theta_{2}-\theta_{3}}{\theta_{1}-\theta_{2}}
$$

In this study, the temperature of the coolant was controlled from 0 to $100{ }^{\circ} \mathrm{C}$ by $10{ }^{\circ} \mathrm{C}$. The temperatures of the heating mediums were maintained at $115^{\circ} \mathrm{C}$ during the measurements. The superheated steam was supplied by the Aqua-gas system by reducing the water supply down to $35 \mathrm{ml} / \mathrm{min}$. In the measurements with the Aqua-gas and the superheated steam, the molar fraction of the water in the gas phase was controlled at $0.980 \pm 0.002$, and it was maintained blow 0.050 in the experiment with the hot air.

(A)

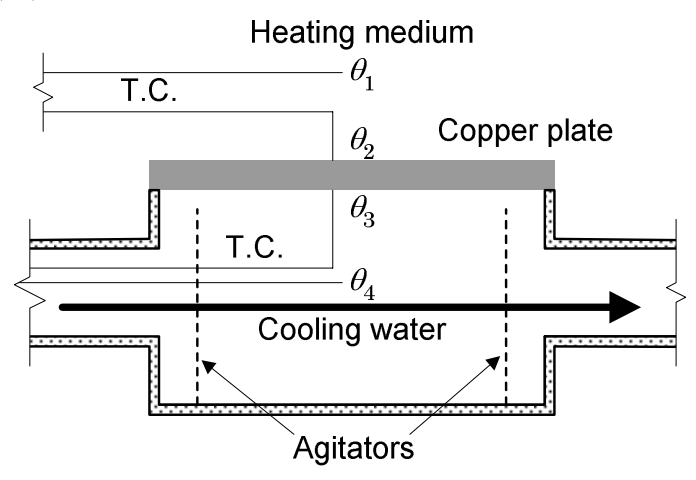

(B)

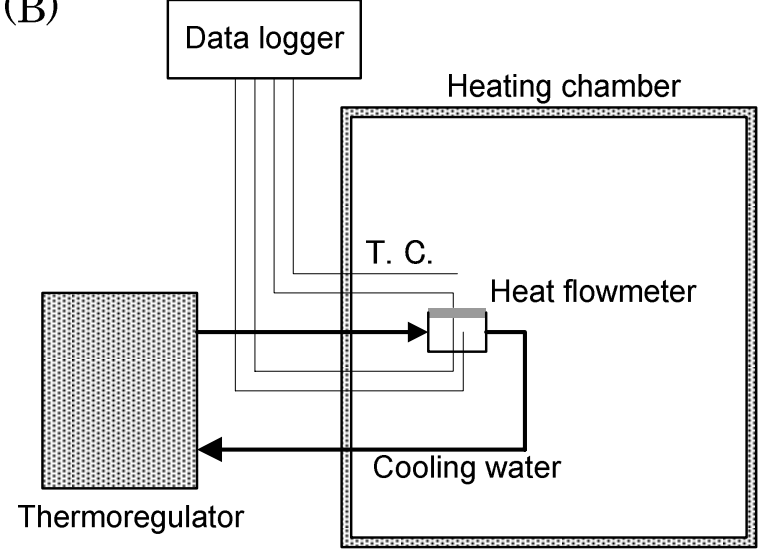

Fig. 2 A schematic drawing of the heat flowmeter (A) and a diagram of the heat flow measurement system (B).

\section{Measurement of the drying rate}

Starch gel sample was used for the examination on the drying properties of the heating mediums. The starch gel has an advantage that the homogeneous sample can be used through the experiments. The water content of the starch gel can be as high as the fresh food, and the starch gel has the similar thermal property with the fresh food. The starch gel was prepared as follow. First, the potato starch was mixed with the distilled water in the ratio of $1: 3$, and it was heated at $90{ }^{\circ} \mathrm{C}$ until it had been gelatinized. After the gelatinization, the gel was frozen and was cut into pieces of $40 \times 40 \times 30 \mathrm{~mm}$. The temperature of the gel sample was maintained $20^{\circ} \mathrm{C}$ before the measurement.

In order to measure the sample weight during the heating, a steel wire basket was prepared. The gel sample was fixed in the basket. The sample in the basket was inserted into the heating chamber, and it was suspended on a hook, which was connected to a load sensor installed on the heating chamber through a hole with a diameter of $1 \mathrm{~cm}$. The experiments were conducted under the same condition with the heat transfer measurement. 


\section{Observation of the micro droplets}

In order to observe the micro droplets inside the Aqua-gas, an Aqua-gas oven with two windows, which enable the observation of the micro droplets by the transmitted light, has been developed. Figure 3 shows the micro droplets observation system. In this system, the micro droplets could be observed through the front window, and the illuminating light was irradiated through the back window. The camera lens could approach to the axis of the nozzle close to $70 \mathrm{~mm}$. A high speed camera (FASTCAM-APX RS 250K, Photron) with a zoom lens (Z16APO, Leica) was used to record the movies of the micro droplets. In the diameter measurement of the micro droplets, the pictures were photographed at 5,000 fps, and the exposure time was $1 / 1,000,000$ second. In the velocity measurement, the frame rate was 90,000 fps and the exposure time was $1 / 1,000,000$ second. The movies were recorded at the vicinity of the nozzle and at the position of every $20 \mathrm{~mm}$ from the nozzle to the nozzle axis direction up to $120 \mathrm{~mm}$.

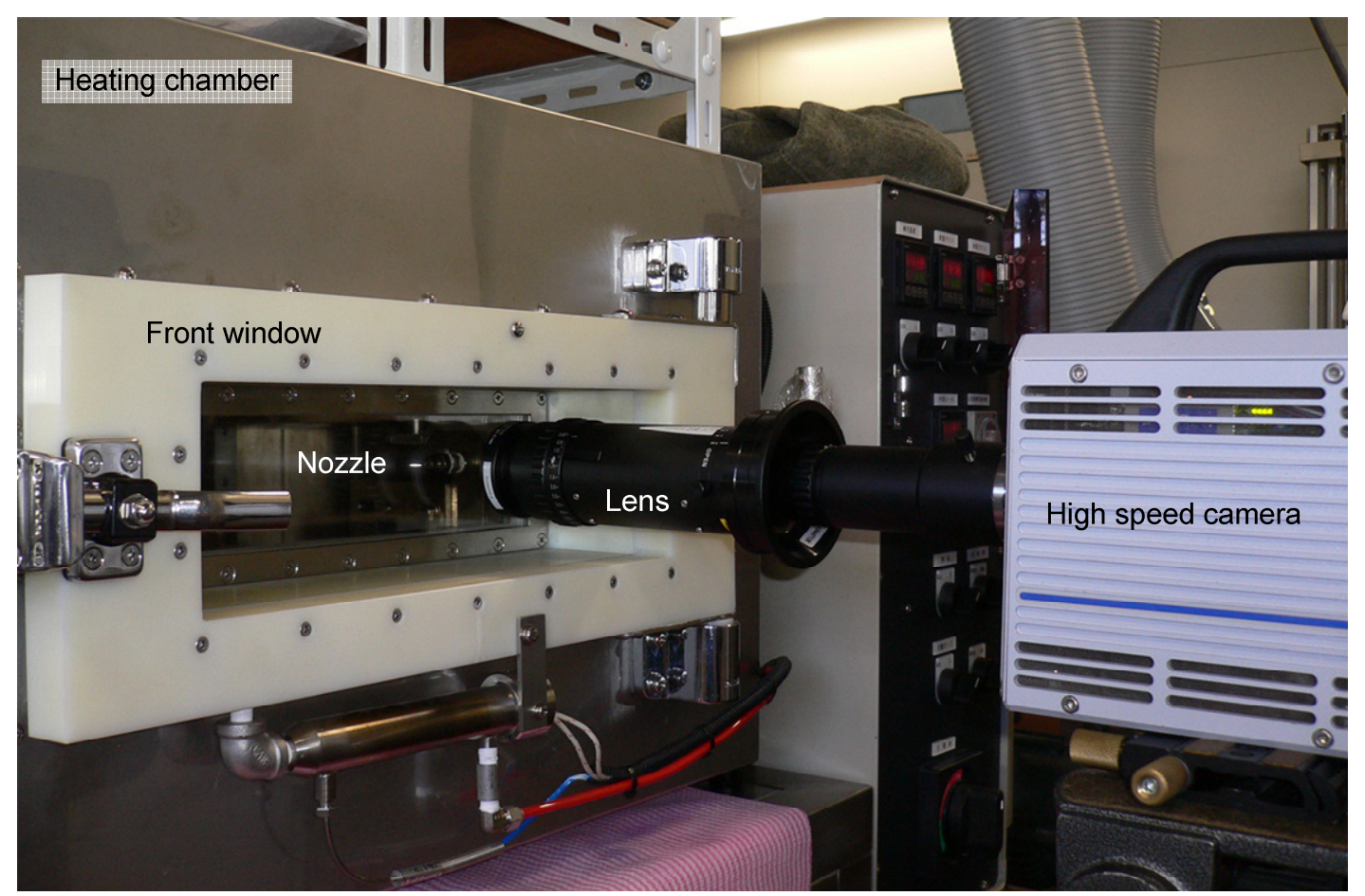

Fig. 3 The Aqua-gas oven system for the observation of the micro droplets and the high speed camera.

The diameters of the micro droplets were analyzed as follow. The profile of the micro droplets was extracted from the picture by the sobel filter and a ridge detection filter developed in this study. The pixel number inside the profile was counted, thus the projected area of the micro droplet was calculated. A radius of the equivalent circle 
with the projected area was calculated, and then the obtained radius was considered the radius of the micro droplet under the assumption that the droplet was sphere. The Sauter's mean diameter (SMD) was calculated from the obtained radiuses of the micro droplets. The velocity of the micro droplets was calculated manually from the displacement of the droplets among the continual pictures. Only the clearly focused micro droplets were analyzed so that the displacement to the depth direction could be ignored.

\section{Determination of the potato blanching time}

The potatoes (c.v. danshaku) were purchased at a local greengrocery in Japan. The temperature of the potatoes was maintained at 7 to $10{ }^{\circ} \mathrm{C}$ before the experiments. The potatoes were blanched by the Aqua-gas oven, a superheated steam oven (SDAHW, Chugoku Maintenance) with approximately $100 \mathrm{~L}$ heating chamber and the boiling hot water. The temperatures of the Aqua-gas and the superheated steam were $115^{\circ} \mathrm{C}$, and the steam was supplied at approximately $50 \mathrm{l} / \mathrm{min}$. The steam was stirred by a fan with a diameter of $200 \mathrm{~mm}$ running at $1200 \mathrm{rpm}$.

Five potatoes with the weight of 140 to $160 \mathrm{~g}$ were used for the temperature measurement for each heating medium. The dimension of the potato was measured by means of a caliper, and the center of the potato was determined. After the determination of the center, the thermocouple was inserted into the center of the potato, and then the temperature at the potato center was measured during the blanching.

The peroxidase activity in the blanched potato was measured as follow. The potatoes were heated by the heating mediums for 5, 10, 15, 20, 25 and 30 minutes, and the potatoes were immersed into cold water immediately after the heating. After the cooling, the potatoes were cut into halves, and then guaiacol solution of $1 \%$ followed by $3 \%$ hydrogen peroxide solution was applied on the sections of the potatoes. The peroxidase active area on the section was colored by the guaiacol. The ratio of the colored area to the section area was calculated from the picture of the potato section by the image processing.

\section{Measurement of the potato quality attributes and the weight loss}

The quality attributes such as the rheological properties, the color and the micro structure of the raw potatoes and the blanched potatoes were measured. The potatoes were blanched for 30 minutes by the heating mediums, and they were cooled by the cold water immediately after heating.

The rheological properties of the potatoes were measured by a creep meter (RE-33005, Yamaden). Breaking stresses and breaking strains of the sliced potato sample of $15 \mathrm{~mm}$ thickness were measured by a plunger of $2 \mathrm{~mm}$ diameter penetrating 
into the potato at $0.5 \mathrm{~mm} / \mathrm{s}$. Three samples were dissected from the central part and from the outer layer of the potato. Five potatoes were examined for each heating medium. The temperature of the sample was ambient room temperature.

The color of the potato was measured by a color meter (CR-300, Minolta). The color of the three positions on the epidermis and three positions of the central part of the potato were measured. The color space system L*a*b* (CIE1976) was employed. Five potatoes were examined for each heating medium.

The micro structure of the potato was observed with a scanning electron microscope (JSM-5600LV, JEOL) at the acceleration voltage of 5 to $10 \mathrm{kV}$, under the degree of vacuum of 10 to $20 \mathrm{~Pa}$. The potato was freeze dried after the blanching. The epidermis and the central part of the potato were observed.

The weight of the potato was measured before and after the blanching, and the weight loss was calculated. Seven potatoes were examined for each heating medium.

\section{Pasteurization of $B$. subutilis spore}

B. subutilis PCI219 was cultivated on agar mediums for two weeks at $37^{\circ} \mathrm{C}$. The cultivated colonies of $B$. subutilis were collected and they were diffused into a pasteurized saline solution. The solution was centrifuged at $29,000 \mathrm{~m} / \mathrm{s}^{2}$ for 10 minutes, and the pellet was diffused into the saline solution again. The solution was heated at $80{ }^{\circ} \mathrm{C}$ for 20 minutes, the B. subutilis spore suspension of $10^{7}$ to $10^{8} / \mathrm{ml}$ was consequently prepared. The suspension of $0.1 \mathrm{ml}$ was applied on the surface of each potato used in this experiment. The potatoes were heated by the heating mediums for 30 minutes. After the heating, the potato was put into a sterile polyethylene bag and immersed into the cold water. The potato was triturated with the saline solution, and the solution was mixed with the agar medium. The active B. subutilis spores in the medium were cultivated for 48 hours at $37{ }^{\circ} \mathrm{C}$, and then developed B. subutilis colonies were counted. Subsequently, active B. subutilis spores in each potato were calculated.

\section{RESULT AND DISCUSSION}

\section{Heat transfer rate of the heating mediums}

The heat transfer rates of the heating mediums were shown in figure 4 . In this study, it was difficult to obtain accurate absolute value of the heat transfer rate as the calibration of the heat flowmeter was difficult; thereby the relative heat transfer rate was shown in the result. In case the temperature of the coolant was $0{ }^{\circ} \mathrm{C}$, the temperature of the heat transfer boundary was $35{ }^{\circ} \mathrm{C}$ in the experiment for the Aqua-gas and the superheated steam, ant it was $4{ }^{\circ} \mathrm{C}$ in the hot air experiment. In case the temperature of the coolant was set to $100{ }^{\circ} \mathrm{C}$, the actual temperature of the coolant 
was $98.5^{\circ} \mathrm{C}$ and the temperature of the heat transfer boundary was 100.1 to $100.2{ }^{\circ} \mathrm{C}$. In the Aqua-gas and in the superheated steam experiments, a dropwise condensation was observed on the boundary when the temperature of the heat transfer boundary was low, which caused extremely larger heat transfer rate than the hot air.

Strong dependencies of the heat transfer rate on the boundary temperature were shown in the superheated steam and especially in the Aqua-gas. The heat transfer rate of the Aqua-gas was greater than that of the superheated steam when the boundary temperature was below $80{ }^{\circ} \mathrm{C}$; however, the heat transfer rates were reversed above 80 ${ }^{\circ} \mathrm{C}$. It was presumably due to the condensed water on the heat transfer boundary. In this study, the condensed water formed droplets on the heat transfer boundary, and they flow down from the boundary continually. In this case, the heat could be transferred to the boundary through the attached droplets and through the superheated steam. The heat flux through the attached droplets may be in proportional to the temperature difference of $\left(100^{\circ} \mathrm{C}-\theta_{2}\right)$, and the flux through the superheated steam was proportional to the temperature difference $\left(115{ }^{\circ} \mathrm{C}-\theta_{2}\right)$. Since the heat transfer rate was calculated from the equation 2 , in other words, the heat transfer rate was obtained by dividing the heat flux by $\left(115^{\circ} \mathrm{C}-\theta_{2}\right)$, it decreased when the boundary temperature approached to $100{ }^{\circ} \mathrm{C}$. In the case of the Aqua-gas, more water was attached on the heat transfer boundary due to the micro droplets in the heating medium, as a result, the Aqua-gas was thought to show the stronger dependency of the heat transfer rate on the boundary temperature.

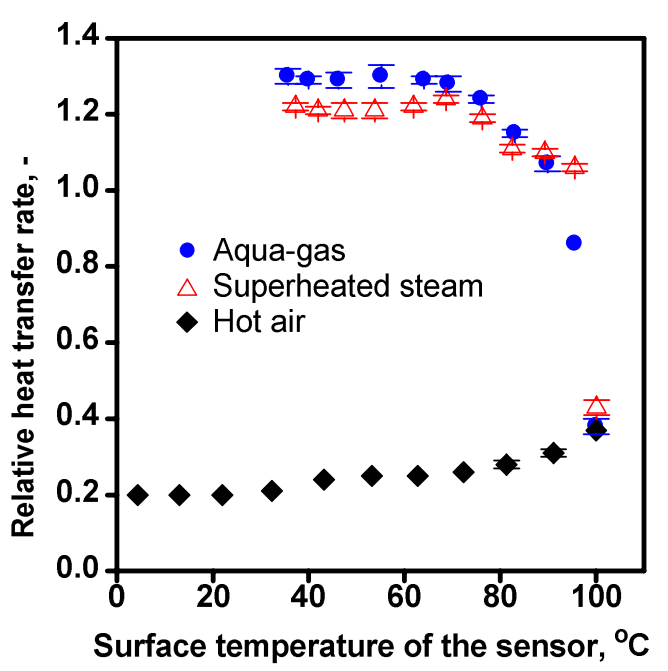

Fig. 4 Dependency of the heat transfer rate of the heating mediums on the temperature at the heat transfer boundary.

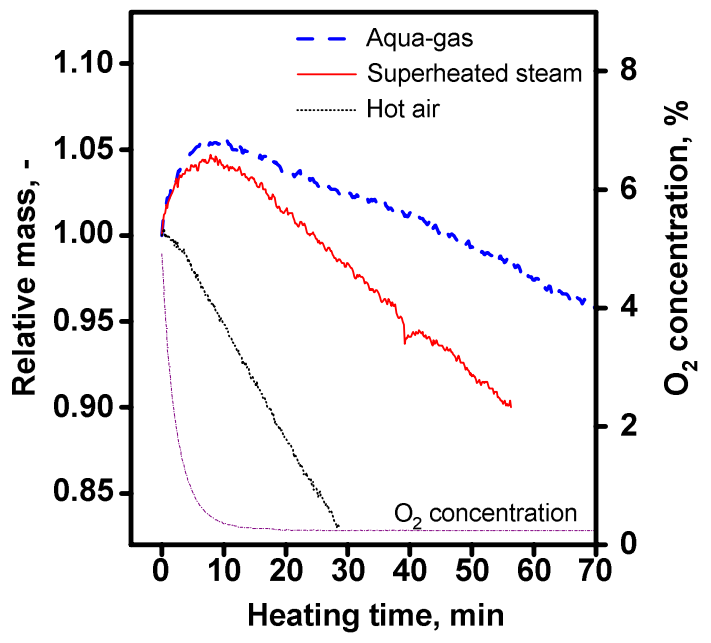

Fig. 5 Examples of the measured mass changes of the model food sample.

\section{Drying rate of the food sample}


The changes in the mass of the model food samples during the heating were shown in figure 5. An oxygen concentration of the Aqua-gas was also shown in the figure 5. Air was mixed into the Aqua-gas when the food sample was inserted into the heating chamber, the $\mathrm{O}_{2}$ concentration consequently increased over than $4 \%$. After 10 minutes the door of the Aqua-gas oven was closed, the $\mathrm{O}_{2}$ concentration decreased to $0.4 \%$ again. In the case of the experiment with the hot air, the sample mass stated to decrease immediately. It was because of the evaporation of the moisture from the food sample. In the case of the Aqua-gas and the superheated steam, the sample mass increased after the sample was inserted into the heating chamber. It was because that the steam condensate on the sample, and the condensed water was absorbed by the sample. The sample mass started to decrease after 10 minutes. The sample temperature increased at that moment, hence the condensation of the steam stopped and the evaporation of the water from the sample started. The mass decrease rate, in other words the drying rate of the sample was lower in the Aqua-gas. It was likely that the micro droplets in the Aqua-gas attached on the food sample and they prevented the dehydration of the sample. The restoration time, which is the time for the sample mass to be restored to the unity, were $27.41 \pm 1.65$ minutes in the superheated steam and $50.31 \pm 4.34$ minutes in the Aqua-gas.

\section{Micro droplets in the Aqua-gas}

The micro droplets in the Aqua-gas photographed by the high speed camera were shown in figure 6 . The picture was taken at the $20 \mathrm{~mm}$ from the nozzle. The micro droplets were clearly observed at the position of 0 to $80 \mathrm{~mm}$ from the nozzle, however the pictures were not satisfactorily obvious at 100 and $120 \mathrm{~mm}$ from the nozzle due to the droplets attaching on the window.

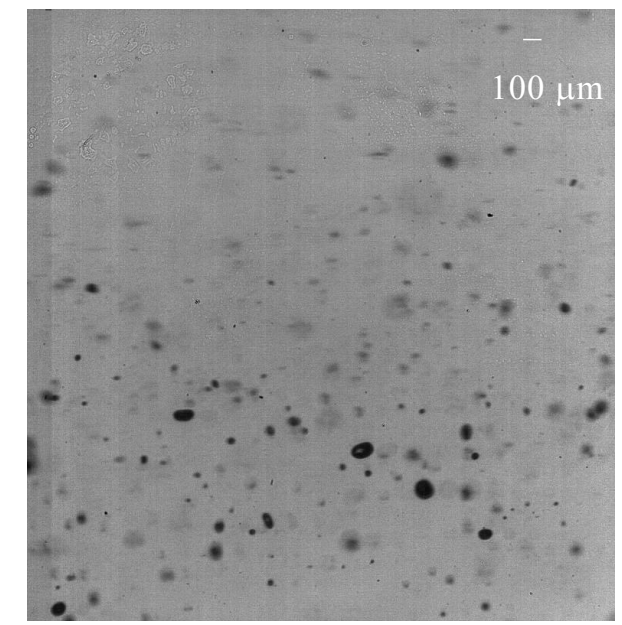

Fig. 6 A photograph of the micro droplets of the hot water in the Aqua-gas.

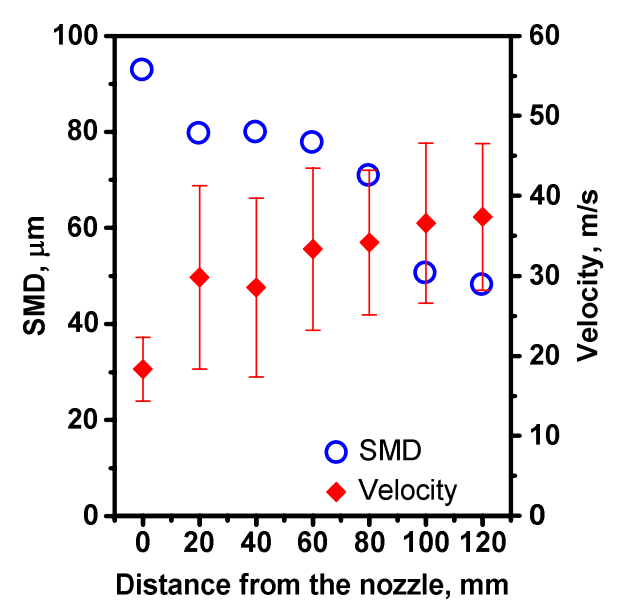

Fig. 7 The SMD and the velocity of the micro droplets in the Aqua-gas. 
Figure 7 showed the Sauter's mean diameter (SMD) and the velocity of the micro droplet. The velocity of the micro droplets increased after they were sprayed especially between the position of 0 and $20 \mathrm{~mm}$ from the nozzle. It was because that the micro droplets were accelerated by the expanding steam outside the nozzle. The SMD of the micro droplets decreased around the position of $80 \mathrm{~mm}$ from the nozzle. It was presumably because that the relative velocity of the micro droplets and the surrounding steam increased, consequently some micro droplets were split by the increased shearing stress from the surrounding steam.

\section{Blanching of the potato}

Although the surface temperature of the potato increased fastest in the Aqua-gas, the temperature at the center of the potato increased in almost same rate. The required time to raise the temperature at the center to $90{ }^{\circ} \mathrm{C}$ by the Aqua-gas, the superheated steam and the hot water were $29.10 \pm 0.96$ minutes, $29.08 \pm 1.07$ minutes and 29.85 \pm .27 minutes respectively, and no significant difference was found in these times. It was because the heat conductivity of the potato was dominant more than the heat transfer rate of the heating medium on the temperature change at the potato center.

Figure 8 showed the relative peroxidase active area on the section of the half cut potato. As the heating time increased, the peroxidase in the potato was inactivated from the outer area of the potato. In all heating mediums, the peroxidase was completely inactivated by the 25 to 30 minutes heating. In case of the potato of 140 to $160 \mathrm{~g}, 30$ minutes heating was thought to be appropriate for the inactivation of the enzymes.

Figure 9 showed the breaking stress and the breaking strain of the central part of the raw potatoes and processed potatoes. The potatoes became soft by the blanching with all heating mediums especially with the hot water. The breaking stress and the breaking strain of the potatoes processed with hot water were low and the potatoes were brittle. There was no significant difference in the rheological properties of the surface of the blanched potatoes. It was because the epidermis of the potato has large influence on the rheological properties of the potato surface and the changes in the rheological properties of the potato epidermis didn't depend on the heating mediums.

Table 1 showed the color of the blanched potato epidermis. The potatoes processed with the hot water became dark and unsaturated color. No significant difference was found in the color of the central part of the potatoes.

Figure 10 showed the micro structures of the potatoes photographed with the scanning electron microscope. In the raw potato and in the potatoes processed with the Aqua-gas and with the superheated steam, structures that seemed to be cell walls were observed. However in the potato processed with the hot water, the surface structure was modified. In the central part of the raw potato, starch grains were observed. In the potatoes processed with the Aqua-gas and with the superheated steam, any starch grain 
was not found due to the gelatinization of the starch. In the potato processed with the hot water, the structure of the potato looked smoother than the potatoes processed with the Aqua-gas and with the superheated steam. It was possible that the some of the potato components eluted to the water.

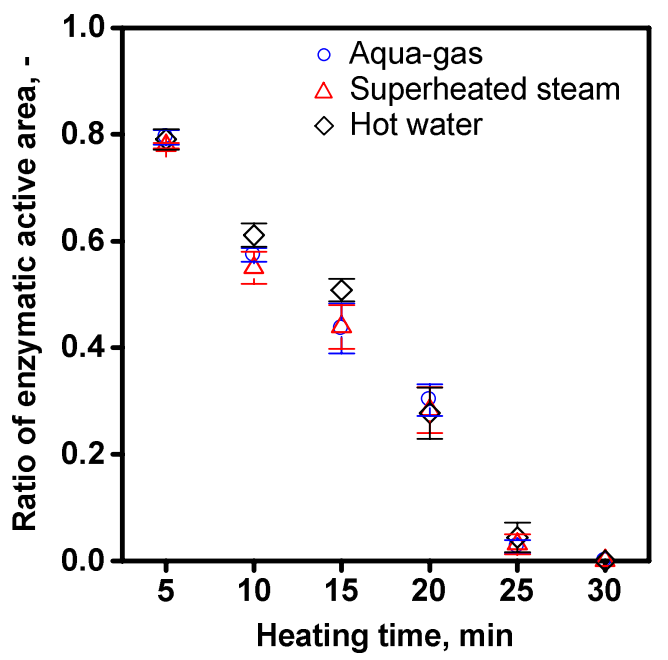

Fig. 8 Enzymatic active area on the section of the potato.

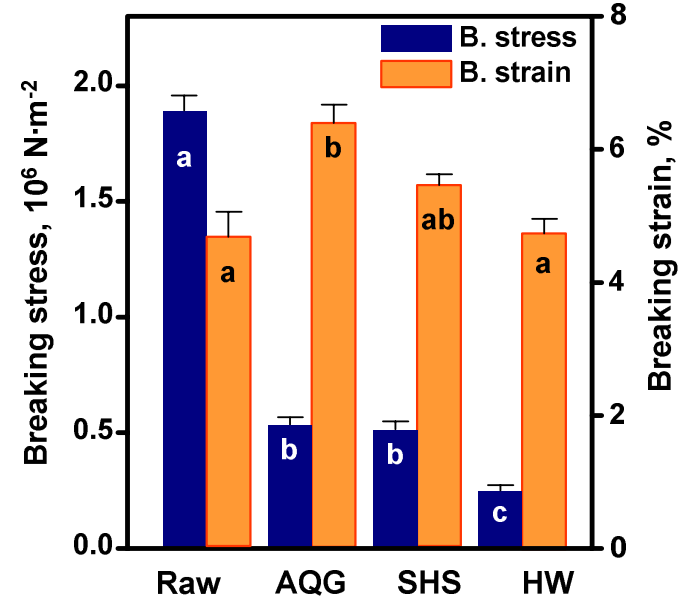

Fig. 9 Rheological properties of the central part of the raw potatoes and the potatoes processed with the Aqua-gas (AQG), the superheated steam (SHS) and the hot water (HW). The bars with the same letters are not significantly different (Turkey's HSD, $P<0.05$ ).

Figure 11 showed the weight loss of the blanched potatoes. In the case of the superheated steam, the weight loss of the potatoes was approximately $3 \%$. However, the weight loss was less than $1 \%$ when the Aqua-gas was used. It was because the micro droplets in the Aqua-gas prevented the potatoes from the drying.

Figure 12 showed the viability of the B. subtilis spores applied on the potato surface. In the case of the hot water, the viability varied from $10^{2}$ to $10^{4} \mathrm{CFU} / \mathrm{stuck}$. It was thought that the hot water had not enough pasteurization power on the B. subtilis spore. In addition, the decrease in the viability was because that the hot water presumably carried away the spores from the potato surface. In other cases, the viability of the B. subtilis spores drastically decreased. In the case of the Aqua-gas, any viable spore was not detected. 
Table 1 Changes in the color of the potato epidermis by the heating process.

\begin{tabular}{cccccccccccccc}
\hline \hline & \multicolumn{3}{l}{$\mathrm{L}^{*}$} & \multicolumn{4}{c}{$\mathrm{a}^{*}$} & \multicolumn{4}{c}{$\mathrm{b}^{*}$} \\
\hline Not heated & 63.70 & \pm & 0.83 & $\mathrm{a}$ & 3.99 & \pm & 0.28 & $\mathrm{a}$ & 34.14 & \pm & 0.36 & $\mathrm{a}$ \\
Aqua-gas & 55.12 & \pm & 0.62 & $\mathrm{~b}$ & -1.46 & \pm & 0.20 & $\mathrm{~b}$ & 22.32 & \pm & 0.53 & $\mathrm{~b}$ \\
Superheated steam & 56.45 & \pm & 0.65 & $\mathrm{~b}$ & -2.06 & \pm & 0.20 & $\mathrm{~b}$ & 23.50 & \pm & 0.51 & $\mathrm{~b}$ \\
Hot water & 52.28 & \pm & 0.79 & $\mathrm{c}$ & -0.48 & \pm & 0.27 & $\mathrm{c}$ & 22.99 & \pm & 0.52 & $\mathrm{~b}$
\end{tabular}

The values with the same letter are not significantly different (Turkey's HSD, $P<0.05$ ).

Epidermis of the potato
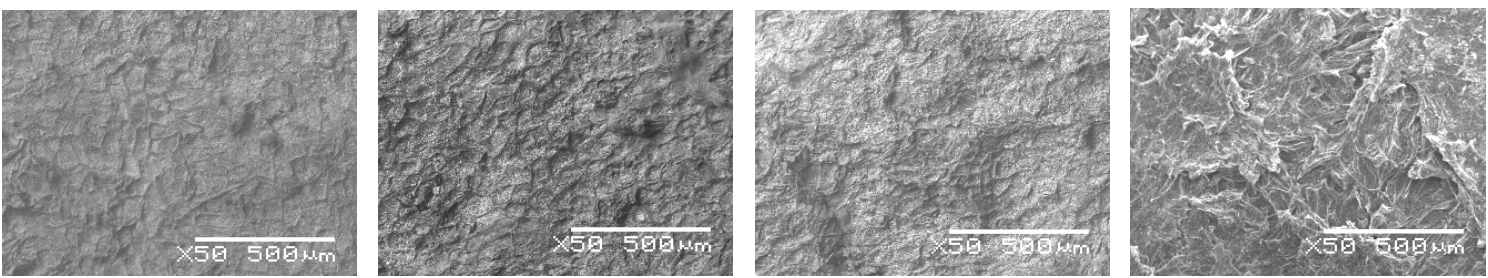

Central part of the potato

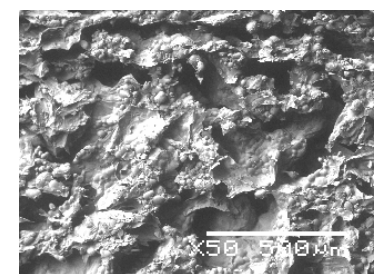

Raw

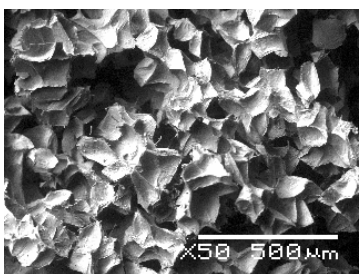

Aqua-gas

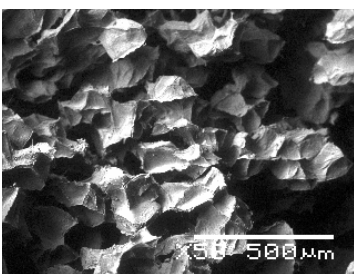

Superheated steam

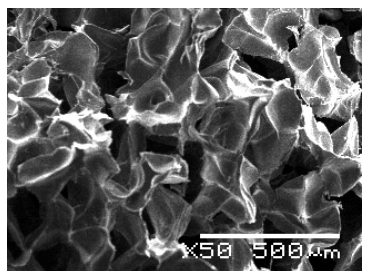

Hot water

Fig. 10 Micro structure of the epidermis and the central part of the potato.

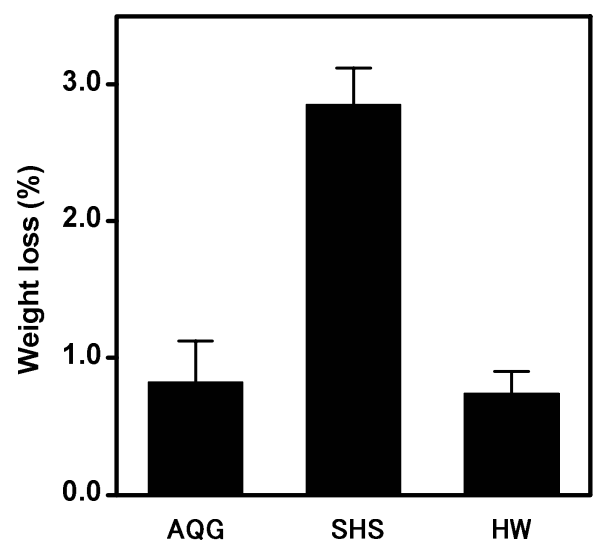

Fig. 11 Weight loss of the potatoes processed with the Aqua-gas (AQG), the superheated steam (SHS) and the hot water $(\mathrm{HW})$.

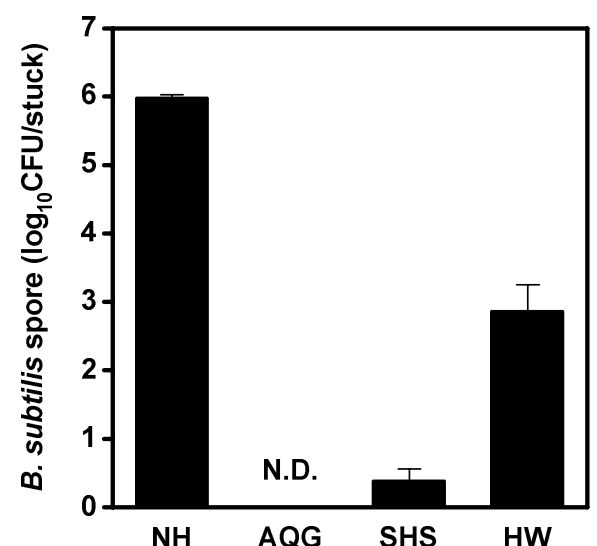

Fig. 12 Viability of the B. subtilis spores on the raw potato and on the blanched potatoes by the Aqua-gas (AQG), the superheated steam (SHS) and the hot water $(\mathrm{HW})$. 


\section{CONCLUSION}

The Aqua-gas showed higher heat transfer rate than the superheated steam in the case the temperature of the heat transfer boundary was low. In addition, it was shown that the drying of the food sample during the heating was prevented by the Aqua-gas. It was thought that the micro droplets in the Aqua-gas had effects on the heat transfer rate and the drying properties of the heating medium.

The potatoes blanched by the Aqua-gas and by the superheated steam had better quality than the potatoes processed with the hot water. The weight loss of the potato processed with the Aqua-gas was smaller than that of the potato processed with the superheated steam. In addition, the effective pasteurization of B. subtilis was achieved by the Aqua-gas. Therefore, it was expected that the Aqua-gas will provide the high quality blanched potato with small weight loss of the potato.

\section{ACKNOWLEDGMENT}

The authors express their appreciation for the financial support provided by a Research and Development Program for New Bio-industry Initiatives from the Bio-oriented Technology Research Advancement Institution.

\section{REFERENCES}

Anthon, G.E. and Barrett D.M., Kinetic Parameters for the Thermal Inactivation of Quality-Related Enzymes in Carrots and Potatoes. J. Agric. Food Chem., 50, 4119-4125 (2002).

Arroqui, C., Rumsey, T.R., Lopez, A. and Virseda, P., Losses by diffusion of ascorbic acid during recycled water blanching of potato tissue. J. Food Eng., 52, 25-30 (2002).

Burg, P. and Fraile, P., Vitamin-C destruction during the cooking of a potato dish. Food Sci. Techol.-Leb., 28, 506-514 (1995).

Burnette, F.S., Peroxidase and Its Relationship to Food Flavor and Quality: A Review. J. Food Sci., 42, 1-6 (1977).

Chuda, Y., Ono, H., Yada, H., Ohara-Takada, A., Matsuura-Endo, C. and Mori, M., Effects of Physiological Changes in Potato Tubers (Solanum tuberosum L.) after Low Temperature Storage on the Level of Acrylamide Formed in Potato Chips. Biosci. Biotechnol. Biochem., 67 (5), 1188-1190 (2003).

Fraile, P. and Burg, P., Reheating of a chilled dish of mashed potatoes in a superheated steam oven. J. Food Eng., 33, 57-80 (1997a).

Fraile, P. and Burg, P., Influence of convection heat transfer on the reheating of a chilled 
ready-cooked dish in an experimental superheated steam cell. J. Food Eng., 33, 263-280 (1997b)

González-Martínez, G., Ahrné, L., Gekas, V. and Sjöholm, I., Analysis of temperature distribution in potato tissue during blanching and its effect on the absolute residual pectin methylesterase activity. J. Food Eng., 65, 433-441 (2004).

Ohara-Takada, A., Matsuura-Endo, C., Chuda, Y., Ono, H., Yada, H., Yoshida, M., Kobayashi, A., Tsuda, S., Takigawa, S., Noda, T., Yamauchi, H. and Mori, M., Change in Content of Sugars and Free Amino Acids in Potato Tubers under Short-Term Storage at Low Temperature and the Effect on Acrylamide Level after Frying. Biosci. Biotechnol. Biochem., 69 (7), 1232-1238 (2005).

Huang, T., Ho, C. and Fu, H., Inhibition of lipid oxidation in pork bundles processing by superheated steam frying. J. Agric. Food Chem., 52, 2924-2928 (2004).

Iyota, H., Konishi, Y., Yoshida, K., Nishimura, N., Nomura T. and Yoshida M., Drying of Carbohydrate Food In Superheated Steam and Hot Air - Characteristics of Coloring of Potato Slice Surfaces -. Kagaku kogaku Ronbunshu, 29 (1), 94-99 (2003).

Iyota, H., Konishi, Y., Inoue, T., Yoshida, K., Nishimura, N. and Nomura, T., Popping of amaranth seeds in hot air and superheated steam. Dry. Technol., 23, 1273-1278 (2005).

Markowski, M., Cenkowski, S., Hatcher, D.W., Dexter, J.E. and Edwards, N.M., The effect of superheated-steam dehydration kinetics on textural properties of Asian noodles. Trans. ASAE, 46, 389-395 (2003).

Severini, C., Baiano, A., De Pilli, T., Carbone, B.F. and Derossi, A., Combined treatments of blanching and dehydration: study on potato cubes. J. Food Eng., 68, 289-296 (2005). 